\title{
Foot massage intervention on chemotherapy drugs induced pain in children with cancer
}

\begin{abstract}
Introduction: Child health continues to be the priority health issue, child hood cancer is not yet a major health issue is not yet a major area of focus.1 Complementary and Alternative Medicine (CAM), significantly, has the potential to affect the lives of many children. Complementary therapies such as reflexology and foot massage could be introduced in healthcare settings as an ideal non-pharmacological method of reducing stress and anxiety and managing difficult symptoms such as pain and nausea. Objective of the study are to .evaluate the efficacy of foot massage intervention on impact of chemotherapy pain among control and experimental group children and comparison of pain scores among control and experimental group children.
\end{abstract}

Methods: True experimental research design was used to assess the efficacy of foot massage intervention. Matched randomization was used to select the samples (same diagnosis in both groups). The samples were children who have diagnosed and admitted for chemotherapy treatment in 8 bedded pediatric oncology unit at Amrita Institute of Medical Sciences, Kochi. The children who met the inclusion criteria, age between 6-18 years and selected drugs which cause moderate or severe pain. National cancer institute common toxicity criteria (NCICT) version 3.0 was used to assess the pain and its severity in mild, moderate, severe and life threatening grades. Pain assessment done before and after administration of chemotherapy both in control $\mathrm{n}=70$ and experimental $\mathrm{n}=70$ children. Before administering the chemotherapy, after administering chemotherapy first 24 hours and end of 48 hours for three assessment. $(10 \mathrm{am}, 2 \mathrm{pm}, 8 \mathrm{pm})$ Foot massage interventions in 6 sessions ( 3 sessions per day 25 minutes per session) were administered.

Results and discussion: For first 24 hours the chemotherapy drugs induced pain among the control group $2(2.8 \%)$ subjects did not have any specific pain, $9(12.8 \%)$ subjects had mild pain, not interfering with function and ADL. 51(72.8\%) subjects experienced pain in a moderate grade. $8(11 \%)$ of the subjects had severe pain interfered with ADL in a severe grade. In experimental group, $15(21 \%)$ did not have any specific pain, 55(78\%) subjects had mild pain not interfering with function and ADL. For next 48 hours among control group, $3(4.2 \%)$ did not have a specific pain, $7(10 \%)$ subjects had mild pain not interfering with function and ADL. 54(77\%) subjects experienced pain of a moderate grade. $6(8.5 \%)$ of the subjects had severe pain interfered with ADL in a severe grade. In experimental group, 24(34\%) subjects did not have any specific pain. $46(65 \%)$ subjects have mild pain not interfering with normal function and ADL.

Conclusion: Children have pain experience after receiving chemotherapy within 48 hours the level of severity of the pain adverse effect was compared by a chi-square test for the experimental group and control group. The ' $t$ ' value 16.22 the mean difference in the pain score of experimental group and control group greater then table value 3.46. On comparison the result is statistically significant at $\mathrm{P}<0.001$.
Volume 2 Issue I - 2017

\section{Chitra P}

Department of Child Health Nursing, Ambo University, Ethiopia

Correspondence: Chitra P, Department of Child Health Nursing,Ambo University, Ethiopia,

Email prof.pchitra@gmail.com

Received: September 22, 2016 | Published: January 23, 2017
Abbreviations: ADL, activities of daily living; CAM, complementary and alternative medicine; FMI, foot massage intervention; NCICT, national cancer institute common toxicity criteria

\section{Introduction}

Child health continues to be the priority health issue, child hood cancer is not yet a major health issue, childhood cancer is a not yet a major area of focus. ${ }^{1}$ Worldwide, the annual number of new cases of childhood cancer exceeds 200,000 and more than $80 \%$ of these are from the developing world. ${ }^{2}$

In recent years, the popularity of alternative medicine has grown due to the increasing popularity of holistic approaches to health that emphasize the integration of body, mind and spirit along with physical symptoms in improving health care and well-being. ${ }^{3}$

Complementary and Alternative Medicine (CAM), significantly, has the potential to affect the lives of many children. Unfortunately, the effectiveness of CAM use remains relatively under researched, and the potential for harmful effects of drug interactions, toxicity or withdrawal that may be experienced by children who are administered CAM therapies in conjunction with, or in lieu of, their prescribed cancer treatment is foreseeable. ${ }^{4}$

A study conducted to determine the frequency, reasons, and factors influencing the use of (CAM) in general and specialty pediatrics within the same geographic area. Of the 281 surveys completed, the CAM use was higher in children with epilepsy $(61.9 \%)$, cancer $(59 \%)$, 
asthma $(50.7 \%)$, and sickle cell disease $(47.4 \%)$ than in general pediatrics $(36 \%)$. Children most often used prayer $(60.5 \%)$, massage $(27.9 \%)$, special vitamins $(27.2 \%)$, chiropractic care $(25.9 \%)$ and dietary supplements $(21.8 \%)$. Parents who used CAM for themselves $(68.7 \%)$ were more likely to access CAM for their children. Most parents $(62.6 \%)$ disclosed some or all of their child's use of CAM to providers. The study confirmed that within the same geographic region, children with chronic and life threatening illness used more CAM therapies than children seen in primary care clinics. The children with cancer used CAM for different reasons than children with non-life threatening illnesses. ${ }^{5}$

A study on massage therapy for children with cancer aimed to determine the feasibility of providing massage to children with cancer to reduce symptoms in children and anxiety in parents. Twenty three children/parent dyads were enrolled; 17 completed all the data points. Children with cancer, aged 1 to 18 years, received at least 2 identical cycles of chemotherapy, and one parent, participated in the 2 period crossover design in which 4 weekly massage sessions alternated with 4 weekly quiet time control sessions. Changes in relaxation and symptoms were assessed among children; anxiety and fatigue were measured among parents. Massage was more effective than quiet time at reducing heart rate in children, anxiety among children aged less than 14 years, and parent anxiety. There were no significant changes in blood pressure, cortisol, pain, nausea or fatigue. The children reported that the massage helped them to feel better, lessened their anxiety and worries, and had longer lasting effects than quiet time. Massage on children with cancer is feasible and appears to decrease anxiety in parents and younger children. ${ }^{6}$

Complementary therapies such as reflexology and foot massage could be introduced in healthcare settings as an ideal nonpharmacological method of reducing stress and anxiety and managing difficult symptoms such as pain and nausea. In a sample of 87 hospitalized cancer patients, a 10-minute foot massage was found to decrease pain levels $(\mathrm{P}=.0001) .^{7}$ An empirical study on the use of foot massage as a nursing intervention among patients hospitalized with cancer .In a sample of 87 subjects, a 10 minute foot massage was found to have a significant immediate effect on the perceptions of pain, nausea, and relaxation when measured with a visual analog scale. $^{7}$

Chemotherapy is the primary treatment modality used to cure many pediatric patients. Chemotherapy is the use of drugs to destroy cancer cells. The goals for use of chemotherapy include reducing the primary tumor size, destroying cancer cells, and preventing metastases or microscopic spread of disease. Chemotherapy is used to destroy these rapidly dividing and mutating cancer cells by interfering with cell division, causing cell death.

Pain is an unpleasant sensory and emotional experience associated with actual or potential tissue damage, or described in terms of such damage $^{8}$ (The International Association for the Study of Pain). It is a major symptom in many medical conditions, and can significantly interfere with a person's quality of life and general functioning. ${ }^{9}$ Chronic pain may be classified as cancer pain or benign. ${ }^{10}$

When a person is non-verbal and cannot self-report pain observation becomes critical, and specific behaviors can be monitored as pain indicators. Behaviors such as facial grimacing and guarding indicate pain, as well as an increase or decrease in vocalizations, changes in routine behavior patterns and mental status changes.
Patients experiencing pain may exhibit withdrawn behavior and possibly experience a decreased appetite and decreased nutritional intake. A change in condition that deviates from baseline such as moaning with movement or when manipulating a body part, and limited range of motion are also potential pain indicators. ${ }^{11}$ The most reliable method for assessing pain in most humans is by asking a question: a person may report pain that cannot be detected by any known physiological measure.

Suggestion can significantly affect pain intensity. About 35\% of people report marked relief after receiving a saline injection they believe to have been morphine. This "placebo" effect is more pronounced in people who are prone to anxiety, so anxiety reduction may account for some of the effect, but it does not account for all of the effect. Placebos are more effective in intense pain than mild pain; and they produce progressively weaker effects with repeated administration.

It is possible for many chronic pain sufferers to become so absorbed in an activity or entertainment that the pain is no longer felt, or is greatly diminished. ${ }^{12}$ Pain is the most common reason for people to use complementary and alternative medicine. ${ }^{13}$ Pain is the main reason for visiting the emergency department in more than $50 \%$ of cases. ${ }^{14}$

\section{Objective of the study are}

i. Evaluate the efficacy of foot massage intervention on impact of chemotherapy pain among control and experimental group children.

ii. Comparison of pain scores among control and experimental group children.

\section{Methods and tools}

True experimental research design was used to assess the efficacy of foot massage intervention. Matched randomization was used to select the samples (same diagnosis in both groups). The samples were children admitted in 8 bedded pediatric oncology units, who met the inclusion criteria, age between 6-18 years, who diagnosed hematological and solid tumors such as Leukemia, Lymphomas. Rhabdo myosarcoma, Osteosarcoma, PNET-Primitive Neural Ectodermal tumors and selected chemotherapy drugs are moderate and severe grade drugs such as Cisplatin, Carboblatin, Cyclophosphamide above $600 \mathrm{mg} / \mathrm{mg} / \mathrm{dl}$ and below $600 \mathrm{mg} / \mathrm{dl}$. National cancer institute common toxicity criteria version 3.0 was used to assess the pain and its severity in mild, moderate, severe and life threatening grades. Pain assessment done before and after administration of chemotherapy both in control $\mathrm{n}=70$ and experimental $\mathrm{n}=70$ children. ${ }^{15}$ Before administering the chemotherapy, after administering chemotherapy first 24 hours and end of 48 hours for three assessment. (10am, 2pm, $8 \mathrm{pm}$ ) FMI in 9 sessions ( 3 sessions per day 25 minutes per session) were administered to the experimental group and routine care to the control group children carried out. ${ }^{16}$

\section{Results and discussion}

In control group15 (21\%) subjects did not have any specific pain. $49(70 \%)$ subjects had mild pain not interfering with normal function and Activities of Daily Living (ADL), 6(8.5\%). subjects experienced moderate grade pain. In the experimental group, 54(77\%) subjects did not have any specific pain. $16(22 \%)$ had mild pain and 
$6(8.5 \%)$ subjects had moderate pain. None of them in the control or experimental group had severe pain experiences.

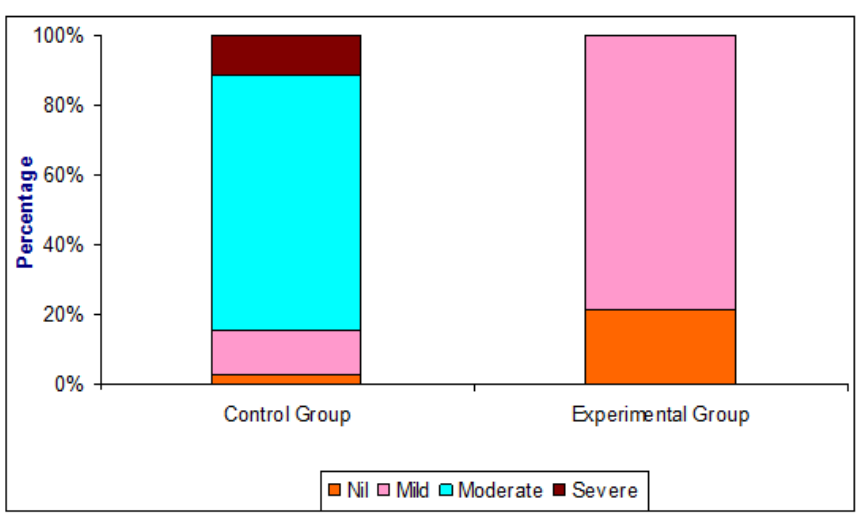

Figure I Pre chemotherapy assessment of pain in control and experimental group children.

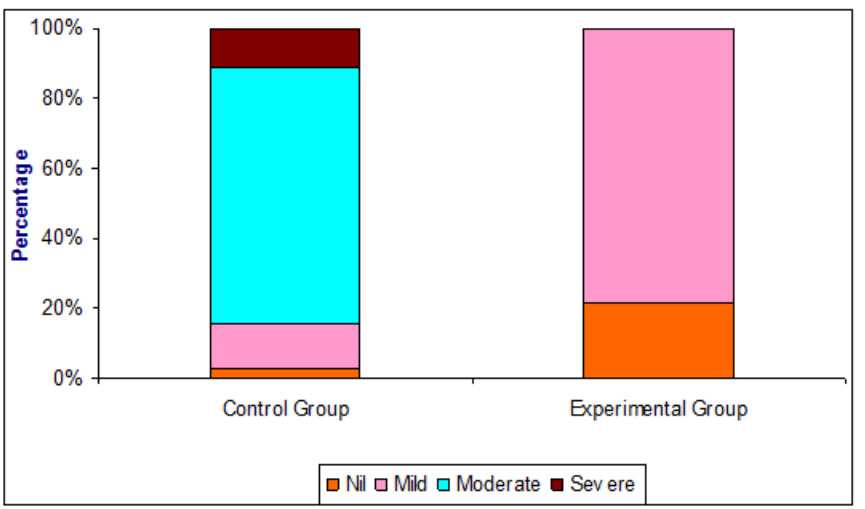

Figure 2 Grade of adverse effect of pain in control and experimental group children-24 hours.

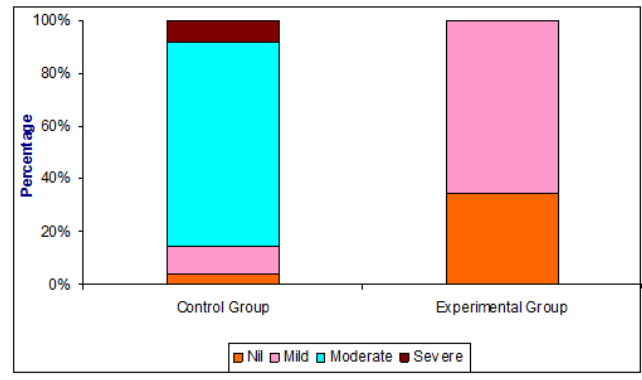

Figure 3 Grade of adverse effect of pain in control and experimental group children-48 hours.

\section{Moderate grade}

In the control group $2(2.8 \%)$ subjects did not have any specific pain, $9(12.8 \%)$ subjects had mild pain, not interfering with function and ADL. 51(72.8\%) subjects experienced pain in a moderate grade. $8(11 \%)$ of the subjects had severe pain interfered with ADL in a severe grade. In the experimental group, $15(21 \%)$ did not have any specific pain, 55(78\%) subjects had mild pain not interfering with function and ADL.

In control group, $3(4.2 \%)$ did not have a specific pain, $7(10 \%)$ subjects had mild pain not interfering with function and ADL. $54(77 \%)$ subjects experienced pain of a moderate grade. $6(8.5 \%)$ of the subjects had severe pain interfered with ADL in a severe grade. In the experimental group, 24(34\%) subjects did not have any specific pain. $46(65 \%)$ subjects have mild pain not interfering with normal function and ADL. An empirical study results supported on the use of foot massage as a nursing intervention among patients hospitalized with cancer .In a sample of 87 subjects, a 10 minute foot massage was found to have a significant immediate effect on the perceptions of pain, nausea, and relaxation when measured with a visual analog scale. $^{7}$

Table I Pre chemotherapy Assessment of pain in control and experimental group children

\begin{tabular}{|c|c|c|c|c|c|c|c|c|c|c|c|c|c|c|c|c|c|c|}
\hline \multirow{3}{*}{$\begin{array}{l}\text { Adverse } \\
\text { Event }\end{array}$} & \multicolumn{8}{|c|}{ Control Group $(N=70)$} & \multicolumn{8}{|c|}{ Experimental Group } & \multirow{3}{*}{$\begin{array}{l}\text { Chi- } \\
\text { Square } \\
\text { Test }\end{array}$} & \multirow{3}{*}{$\begin{array}{l}P \\
\text { Value }\end{array}$} \\
\hline & \multicolumn{2}{|l|}{ Nil } & \multicolumn{2}{|c|}{ Mild } & \multicolumn{2}{|c|}{ Moderate } & \multicolumn{2}{|c|}{ Severe } & \multicolumn{2}{|l|}{ Nil } & \multicolumn{2}{|c|}{ Mild } & \multicolumn{2}{|c|}{ Moderate } & \multicolumn{2}{|c|}{ Severe } & & \\
\hline & No & $\%$ & No & $\%$ & No & $\%$ & No & $\%$ & No & $\%$ & No & $\%$ & No & $\%$ & No & $\%$ & & \\
\hline Pain & 15 & 21.43 & 49 & 70 & 6 & 8.57 & 0 & 0 & 54 & 77.14 & 16 & 22.86 & 6 & 8.57 & 0 & 0 & 44.79 & $<0.001$ \\
\hline
\end{tabular}

Table 2 Grade of adverse effect of pain in control and experimental group children

\begin{tabular}{|c|c|c|c|c|c|c|c|c|c|c|c|c|c|c|c|c|c|c|}
\hline \multirow{3}{*}{$\begin{array}{l}\text { Adverse } \\
\text { Event }\end{array}$} & \multicolumn{8}{|c|}{ Control Group } & \multicolumn{8}{|c|}{ Experimental Group } & \multirow{3}{*}{$\begin{array}{l}\text { Chi-Square } \\
\text { Test }\end{array}$} & \multirow{3}{*}{$\begin{array}{l}\mathbf{P} \\
\text { Value }\end{array}$} \\
\hline & \multicolumn{2}{|l|}{ Nil } & \multicolumn{2}{|l|}{ Mild } & \multicolumn{2}{|c|}{ Moderate } & \multicolumn{2}{|c|}{ Severe } & \multicolumn{2}{|l|}{ Nil } & \multicolumn{2}{|c|}{ Mild } & \multicolumn{2}{|c|}{ Moderate } & \multicolumn{2}{|c|}{ Severe } & & \\
\hline & No & $\%$ & No. & $\%$ & No & $\%$ & No & $\%$ & No & $\%$ & No & $\%$ & No & $\%$ & No & $\%$ & & \\
\hline Pain & 2 & 2.86 & 9 & 12.86 & 51 & 72.86 & 8 & 11.43 & 15 & 21.43 & 55 & 78.57 & 0 & 0.00 & 0 & 0.000 & 102.00 & $<0.001$ \\
\hline
\end{tabular}

Table 3 Grade of adverse effect of pain in control and experimental group children- 48 hours

\begin{tabular}{|c|c|c|c|c|c|c|c|c|c|c|c|c|c|c|c|c|c|c|}
\hline \multirow{3}{*}{$\begin{array}{l}\text { Adverse } \\
\text { Event }\end{array}$} & \multicolumn{8}{|c|}{ Control Group } & \multicolumn{8}{|c|}{ Experimental Group } & \multirow{3}{*}{$\begin{array}{l}\text { Chi-Square } \\
\text { Test }\end{array}$} & \multirow[t]{3}{*}{ PValue } \\
\hline & \multicolumn{2}{|l|}{ Nil } & \multicolumn{2}{|c|}{ Mild } & \multicolumn{2}{|c|}{ Moderate } & \multicolumn{2}{|c|}{ Severe } & \multicolumn{2}{|l|}{ Nil } & \multicolumn{2}{|c|}{ Mild } & \multicolumn{2}{|c|}{ Moderate } & \multicolumn{2}{|c|}{ Severe } & & \\
\hline & No & $\%$ & No & $\%$ & No & $\%$ & No & $\%$ & No & $\%$ & No & $\%$ & No & $\%$ & No & $\%$ & & \\
\hline Pain & 3 & 4.29 & 7 & 10.00 & 54 & 77.14 & 6 & 8.57 & 24 & 34.29 & 46 & 65.71 & 0 & 0.00 & 0 & 0.00 & 105.03 & $<0.001$ \\
\hline
\end{tabular}




\section{Comparison of pain level among subjects in experimental and control group for first 24 hours and 48 hours}

The result revealed that the FMI was effective in the experimental group children before receiving chemotherapy $54(77 \%)$ of them do not have pain for a trial version itself. The significant $\mathrm{P}$ value $<0.001$ indicates the control group children $49(70 \%)$ experienced pain in mild grade. Children have adverse effect of pain after receiving chemotherapy within 24 hours the grade of severity of the pain was compared by a chi-square test for the both groups. The significant $\mathrm{P}$ value $<0.001$ indicates the control group children 51(72\%) experienced pain in moderate grade. The experimental group children $15(21 \%)$ of them do not have any specific abdominal pain due to chemotherapy and 55(78\%) experienced mild pain not interfering with normal function and ADL.

Children have pain experience after receiving chemotherapy within 48 hours the level of severity of the pain adverse effect was compared by a chi-square test for the experimental group and control group. The significant $\mathrm{P}$ value $<0.001$ indicates the control group children $54(77 \%)$ experienced pain at moderate grade. Because of FMI the experimental group children $46(65 \%)$ experienced only mild grade pain.

The study findings supported the present study in a sample of 87 hospitalized cancer patients, a 10 minute foot massage was found to decrease pain levels $(\mathrm{P}=0001)$.

\section{Conclusion}

Children have pain experience after receiving chemotherapy within 48 hours the level of severity of the pain adverse effect was compared by a chi-square test for the experimental group and control group. The ' $t$ ' value 16.22 the mean difference in the pain score of experimental group and control group greater then table value 3.46. On comparison the result is statistically significant at $\mathrm{P}<0.001$. The significant $\mathrm{P}$ value $<0.001$ indicates the control group children $54(77 \%)$ experienced pain at moderate grade. The experimental group received for 9 sessions FMI, 46(65\%) subjects experienced only mild grade pain.FMI is a simple nursing intervention which can be included as pain management strategy for cancer pain and cancer related treatment such as chemotherapy, radiotherapy. Foot massage can be easy to teach the parents, children, care taker executed by an expert. It needs only minimal training, minimal infrastructure change and with minimal resources.

\section{Acknowledgements}

None.

\section{Conflict of interest}

The author declares no conflict of interest.

\section{References}

1. Choudry P. Indian pediatrics and child survival. Indian Pediatr. 2007;44(8):567-568

2. Harif M, Barsaoui S, Benchekroun S, et al. Treatment of B-cell lymphoma with LMB modified protocols in Africa--report of the FrenchAfrican Pediatric Oncology Group (GFAOP). Pediatric blood cancer. 2008;50:1138-1142.

3. Im FS, Nam MR. Effect of foot relexo-massage on the mood sleep and blood pressure of the women elderly. Journal of Morpo Science College. $2005 ; 287-316$

4. Flectcher PC, Clarke J. The use of complementary and alternative medicine among pediatric patients. Cancer Nurs. 2004;27(2):93-99.

5. White JP, Fitzgerald M, Hageness S, et al. Complementary and alternative medicine use in children with cancer and general and specialty pediatrics. J Pediatr Oncol Nurs. 2009;26(1):7-15.

6. White JP, Fitzgerald M, Hageness S, et al. Complementary and alternative medicine use in children with cancer and general and specialty pediatrics. Journal of Pediatric Oncology Nursing. 2009;26(1):16-28.

7. Grealish L, Lomasney A, Whiteman B. Foot massage: A nursing intervention to modify the distressing symptoms of pain and nausea in patients hospitalized with cancer. Cancer Nurs. 2000;23(3):237-243.

8. International Association for the Study of Pain. Pain is an unpleasant sensory and emotional experience associated with actual or potential tissue damage, or described in terms of such damage. The need of taxonomy Pain. 2011;6(3):247-248.

9. Breivik H, Borchgrevink PC, Allen SM, et al. Assessment of pain. $\mathrm{Br} J$ Anaesth. 2008;101(1):17-24.

10. Thienhaus O, Cole BE. Classification of pain. USA: Pain management CRC Press; 2002. 28 p.

11. Jarvis C. Physical examination \& health assessment. Netherland: Elsevier Saunders; 2007. p. 180-192.

12. Melzack R, Wall PD. The challenge of pain. 2nd ed. New York, USA: Springer; 1996. p. 17-19.

13. Astin JA. Why patients use alternative medicine: Results of a national study. JAMA. 1998;279(19):1548-1553.

14. Cordell WH, Keene KK, Giles BK, et al. The high prevalence of pain in emergency medical care. Am J Emerg Med. 2002;20(3):165-169.

15. Alcoser PW, Rodgers Cheryl. Treatment strategies in childhood cancer. $J$ Pediatr Nurs. 2003;18(2):103-104.

16. Working party of the Nuffield Council on Bioethics. The ethics of research involving animals. Nuffield, London: Springer; 2005. 